\title{
AC 2008-570: BIOFUELS IN THE CLASSROOM: USING THE BIODIESEL PROCESS TO DEMONSTRATE CHEMICAL AND PHYSICAL PRINCIPLES
}

\section{Roger Beardsley, Central Washington University}

Roger Beardsley is an assistant professor of Mechanical Engineering Technology at Central Washington University, Ellensburg WA. His interests include many of the renewable energy technologies, with biodiesel processing as his current primary research topic. 


\title{
Biofuels in the Classroom: Using the Biodiesel Process to Demonstrate Chemical and Physical Principles
}

\begin{abstract}
Global environmental, economic, and political factors are generating worldwide interest in biofuel production. However, because biofuel production is still an emerging industry, the study of biofuels is not yet a mainstream topic in most academic programs. Considerable misinformation and confusion exist which impacts acceptance of some biofuels. On the other hand student and community interest in biofuels is extensive, providing a significant opportunity to present accurate information and data.
\end{abstract}

This paper presents a process demonstration that serves as an excellent starting point to describe the conversion of vegetable oil into biodiesel (or Fatty Acid Methyl Ester, FAME). The conversion of vegetable oil into biodiesel is a spontaneous and relatively robust catalyzed chemical process that can be easily adapted into an in-class demonstration or lab experiment using inexpensive equipment and supplies. The basic chemistry of the biodiesel conversion process is outlined to allow calculation of reactant and catalyst amounts, and an acid test procedure is shown which allows for more precise calculation of the catalyst amount. This demonstration addresses the most common biodiesel production problem, that of incomplete reaction equilibrium, and describes a two-step process that produces a more complete reaction. It can also be demonstrated how to use the same ingredients to convert the catalyst into a reactant to block the transesterification reaction and produce undesirable outcomes.

Though the basic demonstration can be easily performed, many levels of complexity can be incorporated into a lesson to demonstrate chemical principles, physical properties, and process constraints. Used as a lecture or lab experiment, this process demonstration may lead to lessons on topics such as balancing chemical reaction equations, converting molar relations into scalable volume measurements, reaction equilibrium and completion concepts, side reactions, and polar vs. nonpolar molecules. Fluid properties of specific gravity and viscosity change during the reaction, and temperature affects the rate at which these changes occur. The effect of these properties on process equipment design can be discussed and calculated, along with material compatibility issues.

Using the biodiesel process as a lecture demonstration or lab activity helps students better understand basic process chemistry and physical properties of fluids, gain experience with process design issues, and gain a better understanding of this biofuel.

\section{Introduction}

Biodiesel is defined as "a fuel comprised of mono-alkyl esters of long chain fatty acids derived from vegetable oils or animal fats, designated B100" ${ }^{1}$. The most common biodiesel molecule is a fatty acid methyl ester (FAME) derived from the transesterification of triglycerides in soybean oil or canola (rapeseed) oil. Biodiesel is formed by chemically splitting a triglyceride molecule in the presence of an alcohol. In splitting the fatty acids off of the triglyceride molecule, the high viscosity of the feedstock oil is reduced to nearly that of petroleum based \#2 Diesel fuel. The 
resulting FAME contains around $11 \%$ oxygen by weight, has an energy density close to that of \#2 Diesel, and a cetane rating typically much higher than the fuel it replaces. Biodiesel is a direct replacement for \#2 Diesel fuel with some premium properties, with quality specifications defined by ASTM Standard D6751-07b.

\begin{tabular}{|l|l|l|l|}
\hline Property & \#2D Diesel Fuel & B100 Biodiesel & Vegetable Oil $^{2}$ \\
\hline ASTM Fuel Standard & D975-07b & D6751-07b & (no fuel spec) \\
\hline Energy Density LHV, min & $131,300 \mathrm{BTU} / \mathrm{Gal}$ & $117,100 \mathrm{BTU} / \mathrm{Gal}$ & $115,000 \mathrm{BTU} / \mathrm{Gal}$ \\
\hline Cetane Number & $40 \mathrm{~min} \mathrm{spec}$ & $47 \mathrm{minimum} \mathrm{spec}$ & 37 to 42 typ \\
\hline Specific Gravity & $0.83-0.86$ & 0.8739 & $0.90-0.93$ \\
\hline Kinematic Viscosity @ 40 C & 1.3 to $4.1 \mathrm{~mm}^{2} / \mathrm{sec}$ & 1.9 to $6.0 \mathrm{~mm}^{2} / \mathrm{sec}$ & 27 to $53 \mathrm{~mm}^{2} / \mathrm{sec}$ \\
\hline
\end{tabular}

Table 1: Comparing Selected Properties of \#2D Diesel Fuel, Biodiesel, and Vegetable Oil

It is possible to operate compression ignition engines directly on unreacted vegetable oil, assuming that the vehicle has been modified with a dual fuel system and oil preheaters. Such vehicles are commonly referred to as running on Straight Vegetable Oil (SVO). There are also a number of high temperature \& pressure refinery type processes (Fischer-Tropsch synthesis, thermal depolymerization, GTL, et al) that can convert biomass to a synthetic liquid diesel fuel. Though these other biomass-derived diesel fuels may be sometimes incorrectly referred to as biodiesel, in this paper the term biodiesel refers only to FAME.

\section{A Single Step Biodiesel Process Demonstration}

The most basic process demonstration can be performed in a discarded plastic soda bottle. This catalyzed reaction will proceed at room temperature and pressure. It is a fairly robust and spontaneous process. A simple reaction performed in a $650 \mathrm{ml} / 20 \mathrm{oz}$ soda bottle can convert 500 $\mathrm{ml}$ of vegetable oil (new or used), $125 \mathrm{ml}$ of methanol, and $4.0 \mathrm{gm} \mathrm{NaOH}$ into about $500 \mathrm{ml}$ of biodiesel with about $125 \mathrm{ml}$ of glycerin byproduct.

The discarded soda bottle should be rinsed clean and then dried before adding $500 \mathrm{ml}$ of vegetable oil. A separate catalyst solution must be prepared by adding the $\mathrm{NaOH}$ to the methanol in a separate container. The $\mathrm{NaOH}$ catalyst must be completely dissolved into the methanol to make the sodium methoxide catalyst solution. This solution is then carefully added to the oil in the soda bottle and the bottle is resealed. The reaction should be started very soon after adding the catalyst solution by shaking the bottle vigorously to cause the oil and catalyst solution to blend.

When the bottle is first shaken it will change from relatively clear amber liquid to a creamy tan emulsion as the catalyst unzips the triglyceride molecules. As the shaking continues the appearance will change from creamy tan to a cloudy amber color, and the speed with which entrained air bubbles rise in the liquid will visibly increase as the viscosity decreases. Once the reaction is underway the bottle can be passed to members of the demonstration audience to shake, thus engaging them in the process. 
The reaction will be mostly done after 15 minutes of shaking. Overnight the glycerin byproduct will fall to the bottom, leaving a transparent amber layer of biodiesel floating on a layer of glycerin. The glycerin layer will range in color from nearly clear (when using new vegetable oil) to a deep dark maroon red (when using waste deep fryer oil). If the feedstock oil is warmed up (approx $110 \mathrm{~F}$ ) before starting the reaction, the reduced viscosity will make the reaction and settling process proceed faster, and the glycerin layer surface will form visibly within an hour.

Typical plastic soda bottle material (PET) may weaken from exposure to the reactants and/or products of the reaction. In most cases this only becomes apparent in the tendency for the bottle neck to fracture where the cap stresses the threads. Applying excessive torque to the cap may result in stress fractures causing the bottle to leak from the thread root. For that reason it is wise to pass a small towel with the bottle if the audience participates in passing and shaking the bottle.

\section{Transesterification of Vegetable Oil}

Transesterification of vegetable oil to biodiesel (FAME) and glycerin has been used commercially for many years as a method to generate glycerin ${ }^{3}$. Because of the low temperature and low pressure nature of the process, it has become popular for biodiesel hobbyists to set up their own garage biodiesel reactors ${ }^{4,5}$.

The triglyceride molecule has a three carbon molecule backbone with one fatty acid molecule attached to each carbon atom in the backbone. The fatty acids have carbon chains ranging from from 8 to 22 carbon atoms long. The various oils and fats are differentiated by the predominance of particular fatty acids in their triglycerides ${ }^{2}$. In the transesterification reaction, one molecule of triglyceride (oil or fat) reacts with three molecules of methanol to give three molecules of fatty acid methyl esters (FAME, or biodiesel) and one molecule of glycerol, as shown in Figure 1.

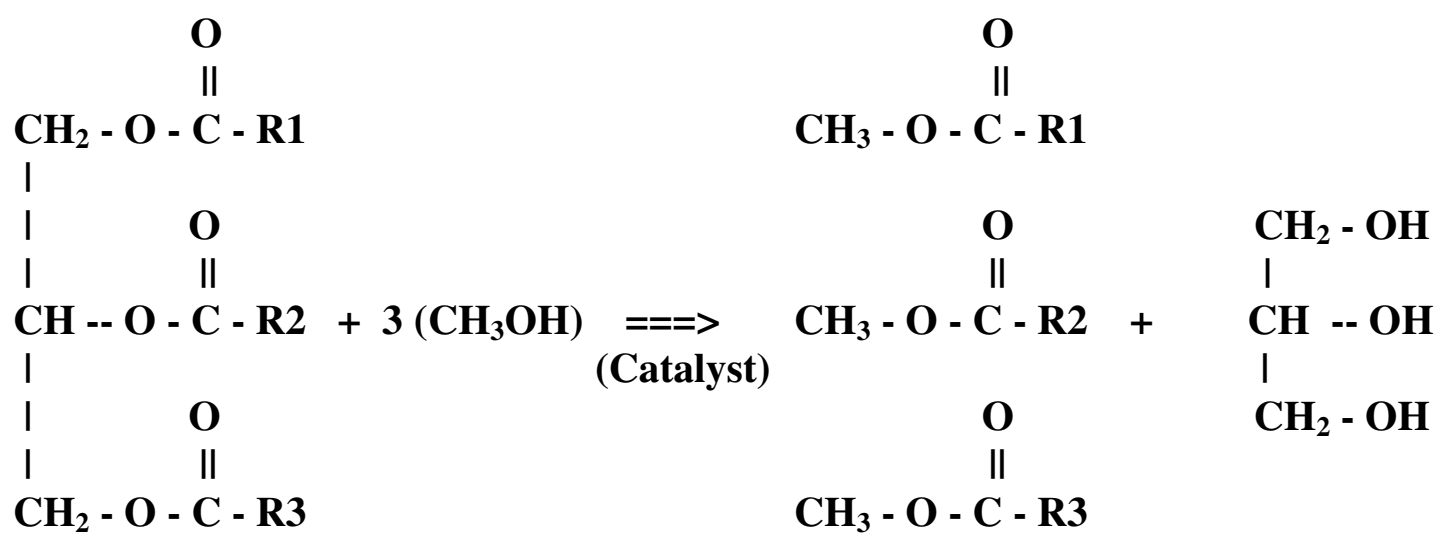

Triglyceride 3 Methanol

3 Biodiesel (FAME) Glycerol

Figure 1: Transesterification Reaction Equation ${ }^{6}$

The fatty acids are represented with nomenclature R1, R2, and R3 in Figure 1. Though there are distinct differences in the sources and flavors of lard, butter, fish oil, olive oil, peanut oil, and 
canola oil, they are all triglycerides. They differ according to the proportion of different fatty acids they contain. The most common fatty acids are 18 carbon chains (Stearic, Oleic, Linoleic and Linolenic), which differ in the number of double bonded carbon atoms (unsaturation). In addition to these 18 carbon fatty acids there are lesser amounts of $8,10,12,14,16$, and 22 carbon fatty acids that are present in varying amounts in different oils and fats.

For this paper the composition of the oil will be standardized as if it was a triglyceride with 3 oleic acid molecules (18 carbon, 1 double bond, ie 18:1), which is the major fatty acid component in canola and peanut oil (18:0 is major component in olive oil; 18:2 is the major component in soybean, safflower and sunflower oil) ${ }^{2}$. This assumption results in a standardized molecular weight of 885.5 grams per mole. Table 2 shows the molecular weights and specific gravity data for selected chemical compounds of interest to biodiesel production.

\begin{tabular}{|l|l|l|}
\hline Compound & $\begin{array}{l}\text { Molecular Weight, } \\
\text { g/mole }\end{array}$ & $\begin{array}{l}\text { Specific Gravity, } \\
\text { kg/Liter @ 20 C }\end{array}$ \\
\hline Sodium (Na+) & 22.99 & - \\
\hline $\begin{array}{l}\text { Sodium Hydroxide } \\
\mathrm{NaOH}\end{array}$ & 40.09 & - \\
\hline Potassium (K+) & 39.10 & - \\
\hline $\begin{array}{l}\text { Potassium Hydroxide } \\
\text { KOH }\end{array}$ & 56.18 & - \\
\hline Methanol $\mathrm{CH}_{3} \mathrm{OH}$ & 32.04 & .7914 \\
\hline Ethanol $\mathrm{CH}_{3} \mathrm{CH}_{2} \mathrm{OH}$ & 46.06 & .789 \\
\hline $\begin{array}{l}\text { Sodium Methoxide } \\
\text { NaOCH}\end{array}$ & 54.02 & - \\
\hline $\begin{array}{l}\text { 25 wt \% Sodium Methoxide } \\
\text { in Methanol Solution }\end{array}$ & - & .944 \\
\hline $\begin{array}{l}\text { Vegetable Oil } \\
\text { (Triglyceride of Oleic Acid) }\end{array}$ & 885.46 & .8988 \\
\hline Oleic Acid FFA & 282.5 & - \\
\hline $\begin{array}{l}\text { Biodiesel } \\
\text { (Oleic Acid Methyl Ester) }\end{array}$ & 296.5 & .8739 \\
\hline Glycerol & 92.10 & 1.2613 \\
\hline Water & 18.02 & 1.000 \\
\hline
\end{tabular}

Table 2: Some Properties of Selected Chemical Compounds in the Biodiesel Process ${ }^{7}$

\section{Reaction Equilibrium and the Two Step Reaction}

Though the overall reaction proceeds to the result shown in Figure 1, the reaction occurs stepwise as indicated in Figure 2. In the basic demonstration reaction outlined above the reaction will approach an equilibrium, at which point the increased glycerin concentration gives rise to a reverse reaction, where glycerol can react back into a monoglyceride at the same rate that monoglycerides are breaking into FAME and glycerol. Because the di- and monoglycerides stay in solution with the biodiesel, small amounts of unreacted tri-, di-, or monoglycerides can result 
in exceeding the free and bound glycerol spec. The biodiesel spec (ASTM D-6751) allows a maximum free or bound glycerol amount of $0.24 \%$ by weight. Since the glycerol content of the initial oil is around $10 \%$, this implies that the transesterification reaction needs to go to at least $97.6 \%$ completion to meet spec.

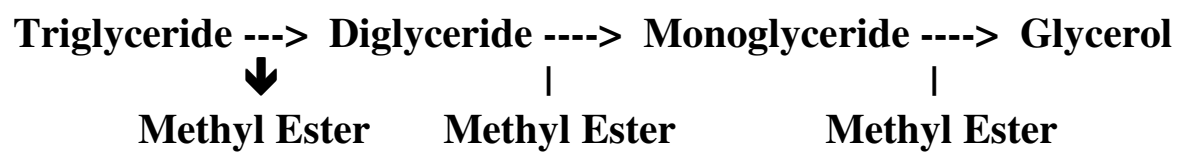

Figure 2: Transesterification Reaction Steps ${ }^{6}$

A two-step transesterification process can reduce the bound glycerol level to within the ASTM quality standard using no additional reactants. The two step process involves an initial reaction using only $80 \%$ of the same total methanol/catalyst mixture. The reactants are allowed to settle and the glycerol layer is removed (a separation funnel is good for this). The remaining methanol/catalyst solution is added to the raw biodiesel and a second reaction is initiated. The removal of the glycerol between the two steps reduces the maximum value of glycerol in the system, which if left in solution can facilitate an increased reverse reaction rate. Compared to the basic one step reaction, the two step reaction can increase the reaction completion from $95 \%$ to over $97.5 \%^{8}$. For a typical demonstration reaction, the first reaction glycerin layer may have a volume of around $60-75 \mathrm{ml}$ (around 12\% of the total volume), and the second reaction may produce another $5-8 \mathrm{ml}$.

The glycerin layer includes some of the excess methanol and much of the catalyst from the reaction. It is an indicator of the reaction progress but should not be used directly to calculate the glycerol product formed without further interpretation. The glycerin layer formed in the second reaction does visibly demonstrate that the initial reaction reached an equilibrium that left unreacted glycerides remaining in solution.

\section{Temperature Effects}

Though the process will still occur at room temperature, the heating up of the oil increases the reaction rate and reduces the viscosity, allowing for easier mixing and faster settling. The temperature does not need to exceed 105F. A hot tap water bath is sufficient. Methanol may vaporize out of an open reaction container if the temperature exceeds $65 \mathrm{C}(149 \mathrm{~F})$, depleting the reaction and causing a potential flammability hazard.

\section{Cold Process Soap Formula}

Vegetable oil and lye can also be combined to make soap. There are a number of different recipes for soap making, but the basic cold process soap making method will be discussed briefly to illustrate the process similarities. Table 4 shows proportions of the various ingredients for a basic cold process soap as compared to the biodiesel demo batch recipe. The cold process soap recipe is based on vegetable (soybean) oil, with a 5\% superfatting level, as defined by the Brambleberry lye calculator ${ }^{9}$. Cold process soap can be made by shaking the preheated ingredients in a soda bottle, eventually resulting in a solid block of soap. 


\begin{tabular}{|l|l|l|}
\hline Ingredient Amount & Cold Process Soap & Biodiesel Demo \\
\hline Vegetable Oil (soybean oil) & $400 \mathrm{ml}$ & $400 \mathrm{ml}$ \\
\hline Lye $(\mathrm{NaOH})$ & $51 \mathrm{gm}$ & $3 \mathrm{gm}$ \\
\hline Water & $150 \mathrm{ml}$ & Nil \\
\hline Methanol & Nil & $100 \mathrm{ml}$ \\
\hline
\end{tabular}

Table 4: Cold Process Soap vs Biodiesel Demo Ingredients

In soap making, the lye is consumed in the reaction and becomes part of the finished product. In biodiesel processing, the lye is converted into a sodium methoxide catalyst and ends up mostly in the glycerin byproduct layer. Soap is immediately formed in the biodiesel process from free fatty acids in the vegetable oil that have broken off the triglycerides. Soap may also be formed if the local concentration of sodium methoxide is too high (ie, when the catalyst is metered in too fast and not mixed well into the oil). Presence of water in the reaction can also facilitate soap formation. Levels of water exceeding $0.5 \%$ can adversely affect the biodiesel process quality and yield ${ }^{10}$. Prevention of soap formation is one of the challenges in biodiesel processing, as soap formation reduces yield, depletes the catalyst, and contaminates the fuel.

\section{Free Fatty Acids and Catalyst Amount}

Many sources recommend using an amount of $\mathrm{NaOH}$ catalyst equal to $1 \%$ of the oil weight ${ }^{6,11}$ which is $9.0 \mathrm{~g} \mathrm{NaOH}$ per liter of oil. Some unpublished experiments by the author have indicated that for lowest raw biodiesel viscosity, an optimum value for catalyst in solution for the initial reaction may be around $0.16 \mathrm{~mol}$ sodium per mol of triglycerides. Using the data in Table 2, this means $6.51 \mathrm{~g} \mathrm{NaOH}$ per liter of oil (3.26 $\mathrm{g} \mathrm{NaOH}$ per $500 \mathrm{ml}$ demo batch, or around $0.72 \%$ of oil weight).

The amount of catalyst in solution is affected by fatty acids in the oil that have already broken off the triglycerides. These free fatty acids (FFA) will immediately form soaps and deplete the catalyst. A liter of feedstock oil will consume $1.27 \mathrm{~g} \mathrm{NaOH}$ for every $1 \%$ FFA present. Virgin vegetable oils can have over $1 \%$ FFA, while used fryer oil may typically have $3 \%$ to $5 \%$ FFA content. Old rancid fryer oil can have FFA content of $15 \%$ or more. For the $500 \mathrm{ml}$ demonstration batch, every $1 \%$ FFA will consume around $0.64 \mathrm{~g} \mathrm{NaOH}$. A FFA level of $6.3 \%$ in the feedstock oil would completely consume the $4.0 \mathrm{~g}$ of catalyst recommended for the basic reaction. Testing for the FFA level allows optimization of the catalyst amount in solution.

\section{Acid Test to Determine Catalyst Consumption}

An official test for determining FFA in vegetable oil is American Oil Chemist Society test AOCS Ca 5a-40, Free Fatty Acid in Commercial Oils. The result of the test is given as mg KOH per gram oil necessary to bring the oil sample to a neutral $\mathrm{pH}$. Every $1 \%$ FFA in the feedstock oil results in a reading of approximately $2 \mathrm{mg} \mathrm{KOH}$ as determined by this test.

The AOCS method requires specialized lab equipment and chemical supplies. An alternative method proposed by Tickell uses more commonly available equipment and materials, and gives a result that is easier to interpret ${ }^{11}$. The Tickell method dissolves $1.00 \mathrm{~g}$ of NaOH into 1.00 liter of 
distilled water, giving $1 \mathrm{mg} \mathrm{NaOH}$ per $\mathrm{ml}$ of solution. In a separate container $1.0 \mathrm{ml}$ of untreated oil is added to $10 \mathrm{ml}$ of isopropyl alcohol. The lye solution is measured and added into the oil solution a drop at a time until the $\mathrm{pH}$ changes to 8 or 9 (it might start at a pH of 5 or so; the ph change can happen rapidly). The $\mathrm{pH}$ can be measured using a small $\mathrm{pH}$ meter, litmus paper, or an indicator solution such as phenolphthalein. The number of $\mathrm{ml}$ of lye solution added to neutralize the sample is the same number of grams of $\mathrm{NaOH}$ necessary to neutralize the FFA in 1 liter of the untreated oil. There will be 1\% FFA present in the feedstock oil for every $1.27 \mathrm{ml} \mathrm{NaOH}$ solution needed to neutralize the sample.

The Tickell method may under-report the acid level by $10 \%$ to $30 \%$ because the alcohol emulsifies the oil sample but does not truly dissolve it. As a result some FFA may remain inaccessible within oil droplets suspended in the emulsion. Adding $10 \mathrm{ml}$ toluene to the alcohol solvent dissolves the oil and increases the acid value. The alcohol absorbs the water carrying the $\mathrm{NaOH}$, while the toluene dissolves the oil sample into solution. The alcohol and toluene are soluble in each other, so by using both solvents all components will dissolve into solution.

\section{Catalyst Preparation}

Dissolving the $\mathrm{NaOH}$ into the methanol takes time (15 minutes of agitation or more) and will generate some heat (heat of solution for $\mathrm{NaOH}$ ). Any $\mathrm{NaOH}$ that is not fully dissolved will react directly with the oil to form soap. The methanol and $\mathrm{NaOH}$ solution forms a sodium methoxide catalyst $\left(\mathrm{NaOCH}_{3}\right)$ which is reactive, corrosive, toxic, and flammable, combining the toxic and hazardous properties of the $\mathrm{NaOH}$ (lye) and methanol reactants. Potassium hydroxide may also be dissolved in methanol to make a catalyst solution. To maintain an equivalent molar ratio, the mass of $\mathrm{KOH}$ used must be 1.4 times the mass of $\mathrm{NaOH}$ being replaced.

A prepared solution of sodium methoxide (or potassium methoxide) can also be obtained from chemical suppliers, and is commonly used commercially. It is typically sold as a solution in methanol with $25 \% \mathrm{NaOCH}_{3}$ by weight. The commercially prepared solution has the advantage that it is free from moisture, while the catalyst prepared by dissolving $\mathrm{NaOH}$ or $\mathrm{KOH}$ will produce 1 molecule of water for every catalyst molecule. This catalyst reaction can result in a moisture content of $0.3 \%$ of total weight of reactants, and as mentioned above the reaction is affected by water content in excess of $0.5 \%$.

\section{Safety Precautions}

Biodiesel itself has low levels of toxicity and flammability hazard. FAME has even been proposed for cleaning petroleum spills ${ }^{12}$, where it will dissolve spilled petroleum, and the solution can be skimmed out of the water and recovered with the dissolved petroleum for use as a fuel. A lighted match dropped onto an open surface of finished biodiesel will go out.

While the vegetable oil and finished biodiesel do not pose significant safety hazards, keeping large quantities of methanol on hand does pose a flammability risk. This has been the cause of most serious biodiesel related accidents ${ }^{13}$. Methanol is also toxic in large amounts and can be absorbed through the skin and inhaled vapors. Excess methanol from the reaction and the catalyst end up primarily in the glycerin layer. 
The lye-based catalyst is corrosive, and when added to methanol the catalyst solution becomes toxic, corrosive, and flammable. This sodium methoxide solution is the most dangerous compound in the process. Exposure to this compound in the demonstration is limited to the act of pouring the catalyst solution into the oil and capping the reaction container.

Precautions to be considered for the demonstration should include safety glasses or goggles, a towel for spills, and a covered container large enough to hold the volume of the batch in the event of bottle material failure. When larger batches are being made, proper ventilation may be an additional concern, along with gloves and protective clothing. Vegetable oil and biodiesel will stain clothing but not harm it otherwise. Biodiesel and its component chemicals will soften and degrade many common safety gloves made with natural rubber, nitrile, neoprene, latex, and butyl. Chemical resistant safety gloves made with polyethylene, PVC, or Viton should be unaffected.

\section{Reactant Sources}

The least expensive source for feedstock oil is a restaurant with a deep fryer. Each deep fryer contains about 4 gallons of oil and is typically changed every week, and sometimes more often depending on use. Most restaurants have at least one and more commonly two or more deep fryers, and disposing of the used grease is an expense for the restaurant. It is best to arrange for the oil direct from the deep fryer as opposed to collecting it from an outside grease dumpster, where it may be contaminated with water from condensation or rain.

For small quantities, commercially pure methanol is available in auto parts stores as a water absorber for fuel tanks. HEET brand fuel moisture absorber in the yellow bottle is one such product. Larger quantities of methanol racing fuel may be available from motor sports competitors or fuel distributors.

A commercial grade Sodium Hydroxide powder was commonly available in grocery stores until recently, sold as Red Devil Lye drain opener. Current sources for sodium hydroxide powder are soap making craft suppliers or lab chemical suppliers.

\section{Incorporating the Demonstration in Lessons}

The basic biodiesel process demonstration can be used as an audience participation activity in a lecture or presentation on biofuels or other alternative energy topics. There are also a number of ways to use the biodiesel process to demonstrate basic scientific principles. The following topics can be used in lab activities:

1. Converting Molar Values to Volume Measurements: Calculate how many moles of triglyceride are in a liter using the specific gravity and molar mass data. Also determine the volume of methanol consumed in the process of converting one liter of oil to FAME, and the methanol volume needed for the $100 \%$ excess methanol in the reaction. Scale the numbers from 1 liter to a convenient batch size. 
2. Demonstration of Reaction Equilibrium: After settling an initial reaction and separating the glycerin layer, the glycerin that falls after the second reaction demonstrates that there are still some unreacted glycerides remaining in the raw biodiesel layer from the first reaction.

3. Uncatalyzed Reaction: What happens if the methanol and oil are shaken together without a catalyst? This can lead into a discussion of what catalysts do, how they work, etc.

4. Acid Test Procedure to Calculate Catalyst: Follow the AOCS or Tickell method for determining the FFA content of the feedstock oil. Use the information to calculate the sacrificial lye amount and add that amount to the catalyst solution concentration target of $0.16 \mathrm{~mol}$ per liter of oil.

5. Heat of Solution: The heat of solution for dissolving $\mathrm{NaOH}$ into methanol is exothermic and releases a measurable amount of heat. Predicting the rise in temperature of the catalyst solution could be part of the demonstration or lab activity.

5. Chemical Analysis of Raw Biodiesel and the Glycerin Layer: Where does the catalyst end up? How much methanol is excess to the reaction and where does it go? Testing the raw biodiesel to compare to the ASTM specs would also be an option for labs equipped with appropriate equipment.

6. Material Property Effects: Biodiesel is known to weaken and swell natural rubber elastomers such as Buna-N O-rings and hoses, but not Viton elastomers. Polyvinyl Chloride hose (PVC) seems to weep biodiesel after a time and may be weakened also. There is also evidence that the process may weaken the PET plastic in soda bottles. Polypropylene and high density polyethylene (HDPE) appear visually unaffected. Ultimate and yield strength for some or all of these materials may be affected by the biodiesel or the process chemicals. A materials lab project could investigate the effects of biodiesel and its process compounds on various plastics.

7. Viscosity Measurements: Fluids labs with access to viscometers could test the viscosity of the reactants and reaction products as a lab exercise. The fluids involved include methanol, FAME, vegetable oil, and glycerin, giving a wide range of fluid viscosity to test with significant temperature variation effects.

8. Effect of Varying Viscosity on Process Equipment Design: The viscosity of the reactants changes significantly during the initial phase of the reaction. A fluids lab project could calculate the pipe size required for a consistent Reynolds number (pick a high value for mixing in the reaction phase) for the range of viscosity levels in the process. The pressure drop and pumping power required for every $10 \mathrm{ft}$ of pipe at each viscosity value could also be calculated.

9. Process Equipment Design for Continuous Flow Process: Based on estimates of the reaction time from the demonstration scale reaction and a continuous process target flow rate, students could determine the diameter and length of piping for the initial reaction, keeping the Reynolds number high for mixing. The conceptual design of a very low Reynolds number section to passively separate the glycerin layer could be another design project. Pump selection and pricing could also be incorporated into the design project. 


\section{Conclusion}

The biodiesel process demonstration is a spontaneous and robust chemical process that can be used to spark discussion about alternative fuels, demonstrate chemical and physical principles, and show how those principles apply to the design of process equipment. The biodiesel process can give context to chemical concepts, such as calculating molar values and converting them to mass and volume measurements. The fluids involved have a wide range of density and viscosity values that can be explored and discussed in a lab or lecture setting. The effect of these properties on process design and equipment selection can also be a point for discussion.

Opportunities exist for incorporating various aspects of the transesterification process into labs and student design projects. Many students are enthusiastic about working with and learning about biofuels, and the demonstration that has been outlined can spark student interest and help them better understand the many related scientific and engineering principles that are embodied in the conversion of vegetable oil into biodiesel.

\section{References}

(1) American Society for Testing and Materials, Standard Specification for Biodiesel Fuel (B100) Blend Stock for Distillate Fuels ASTM Standard D6751-07b ASTM International, West Conshohocken, PA 2007

(2) Knothe, G., Van Gerpen, J. \& Krahl, J. (Eds.). (2005). The Biodiesel Handbook. Champaign, Illinois: AOCS Press. p. 282 Table A-3

(3) Van Gerpen, J., Shanks, B., Pruszko, R., Clements, D., \& Knothe, G. ( 2004, July). Biodiesel production technology. (NREL/SR Publication No. 510-36244). National Renewable Energy Laboratory, Boulder CO. p. 56

(4) Local B100 Website, http://www.localb100.com, accessed Dec 29,2007

(5) Journey to Forever website, http://journeytoforever.org/biodiesel_vehicle.html, accessed Dec 29, 2007

(6) Van Gerpen, J., Shanks, B., Pruszko, R., Clements, D., \& Knothe, G. ( 2004, July).Biodiesel production technology. (NREL/SR Publication No. 510-36244). National Renewable Energy Laboratory, Boulder CO. p. 1

(7) CRC Handbook of Chemistry and Physics, CRC Publications

(8) Canakci, M. \& Van Gerpen, J. (2003). A pilot plant to produce biodiesel from high free fatty acid feedstocks. Transactions of the American Society of Agricultural Engineers (ASAE) Vol. 46(4): 945-954. p. 948

(9) Brambleberry, Inc website, http:// www.brambleberry.com /lye_calc_1.php, accessed Dec 14, 2007

(10) Canakci, M. \& Van Gerpen, J. (2001). Biodiesel Production from Oils and Fats with High Free Fatty Acids. Transactions of the American Society of Agricultural Engineers (ASAE) Vol. 44(6): 1429-1436.

(11) Tickell, J. (2003). From the fryer to the fuel tank. New Orleans: Joshua Tickell Media Productions. p. 65-66

(12) Cytoculture Inc Website http://www.cytoculture.com/process.html, accessed

(13) Fire Destroys American Biofuels Facility in Bakersfield Calif. Biodiesel Magazine, BBI international, Grand Forks, ND April, 2006 